\title{
ARTICLE \\ Running Head: Business Travel and Perceived Stress Psychological Stress among Business Travelers in Malaysia
}

\author{
Dhiviya Karunaharan \\ International University of Malaya-Wales, Malaysia
}

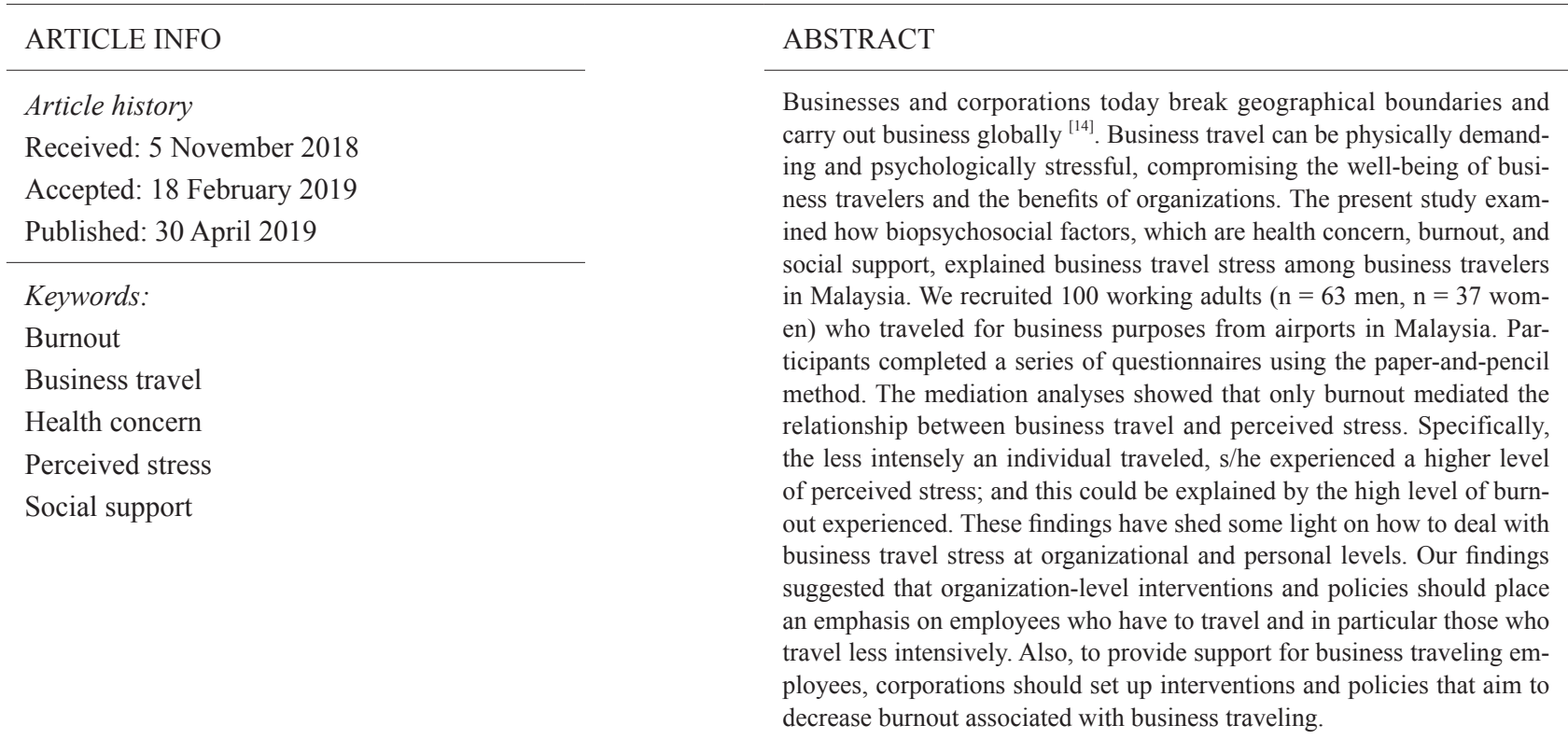

\section{Psychological Stress among Business Trav- elers in Malaysia}

$\mathrm{B}$ usinesses and corporations today have increasing needs to carry out business action plans globally ${ }^{[14]}$. The Malaysian economy focuses a lot on international trading that involves interacting with people face-to-face ${ }^{[31]}$. Therefore, business assignments generally encompass making business trips. Business travel can be exciting and fulfilling and yet psychologically and physically demanding. The complications of travel, such as parting from family, risks for contracting transferable viruses, and alterations in sleep and eat patterns ${ }^{[24]}$, can be perceived as stress to business travelers. In the long run, stress may increase business travelers' risks for diseases, such as cardiovascular disease ${ }^{[1]}$. Prolonged exposure to stress can also have detrimental effects on the performance of business travelers, such as withholding effort and refuse to cooperate ${ }^{[37]}$. Demonstrating these negative work attitudes during business travel will compromise organization's image and potential profit. Previous studies have reported on the harmful effects of increased stress on

*Corresponding Author:

Dhiviya Karunaharan,

International University of Malaya-Wales, Malaysia;

Email:dhiv_karu@hotmail.com. 
productivity. Stress prevention was found to have found to not only reduce cost but also to improve productivity. Addressing stress is thus fundamental not only to a company duty of care responsibilities but also as a strategic component to managing the workforce.

Therefore, understanding the underlying mechanisms of the association between business travel and stress is important in dealing with travel stress at organizational and personal levels. The present study aimed to investigate how business travel is associated with perceived stress in Malaysia and how the perception of biopsychosocial factors explains the association. This study has chosen to define a new set of key performance indicators in order to quantify the hidden costs of business travels to measure successful travel management. Understanding the mechanism of stress and its impact on both traveller and the wider organization sets a new frontier in business travel optimization.

\section{Business Travel Stress}

Research investigating business travel stress used various ways to quantify business travel. For instance, Batt and Valcour (2003) ${ }^{[8]}$ operationalized business travel as a dummy variable, which is whether or not business travel is a regular part of their job. Striker et al. (1999) ${ }^{[42]}$ measured business travel as whether or not employees travel across different time zones, and how frequent and how long was the travel. Voydanoff (2005) ${ }^{[45]}$ quantified business travel as the number of nights in the past three months when participants were away from home for business purposes.

Research has linked business travel to a higher level of stress (e.g., Espino, Sundstrom , Frick, Jacobs, \& Peters, $2002^{[22]}$; Liese, Mundt, Dell, Nagy, \& Demure, $1997^{[33]}$ ). For instance, Liese and colleagues ${ }^{[33]}$ examined the effect of work-related travel on the employees of the World Bank and reported that employees who traveled for business purposes filed more medical claims than those who did not travel, especially claims for stress-related psychological disturbances.

\section{Underlying Mechanisms}

The next step to understanding business travel stress is to understand its underlying mechanisms. Physical and social environmental factors can be one of the mechanisms that explain travel stress. At work, making work arrangements, preparing for business travel prior to travel ${ }^{[17]}$, and performing follow-up after travel, such as paperwork, are considered sources of stress ${ }^{[42]}$. At home, to lessen spouses' burden while being physically absent for days, travelers have to make extra efforts to make arrangements for their home responsibilities, such as looking for a babysitter ${ }^{[17]}$. During business travel, constant changes in environment and alterations in everyday routine to which business travelers need to adjust can lead to poor adjustment and stress ${ }^{[24]}$.

Although rarely explored, psychological factors can be a mechanism that explain travel stress. According to the cognitive appraisal theory of stress ${ }^{[25]}$, the perception of stress is essentially a product of one's appraisal of the environment, and the appraisal focuses on the demands (e.g., workload) and resources available (e.g., personal skills). One perceives an event to be stressful when the demands are thought to surpass the resources available. For instance, stress can arise when a business traveler believes that her/his personal skills and support do not meet the essential demands of business travel. In other words, the environmental factors that might serve as demands on business travelers could be seen as stress or merely neutral stimuli depending on how business travelers appraise them.

This study, as an exploratory study, aimed to examine the underlying psychological mechanisms of business travel stress based on the cognitive appraisal theory ${ }^{[25]}$ This study took a more holistic approach to examine the mechanisms from three aspects, namely perceived biological, psychological, and social factors. The perceived biological factor focused on how business travelers perceive business travel to affect their health (i.e., health concern); the psychological factor focused on psychological burnout; the perceived social factor looked at social support.

\subsection{Health Concern}

To date, there has only been a minute amount of research that investigated the association between business travel and health concern. Most of these studies associated travel with actual health issues faced by travelers. These health issues include infected with physical illness, such as infectious diseases ${ }^{[12]}$. The findings from this line of research resonated a study ${ }^{[33]}$ that investigated insurance claims made by business travelers. Specifically, relative to their colleagues who did not travel, business travelers made more insurance claims for physical illness.

Not only does having actual health issues increase perceived stress, having concern for health may also increase perceived stress. In a study by Espino and colleagues (2002) ${ }^{[22]}$, more than half of the international business travelers who participated in the study were concerned about how business travel affected their physical health. In written comments, many of these respondents identified 
worrying about getting sick during the trips, infected with parasites, exhaustion, long work hours during the trips, and jet lag as main issues. The concern for health increases the stress level of business travelers (Espino et al., 2002 ${ }^{[22]}$; Striker et al., $1999^{[42]}$ ).

Individuals may appraise business travel-related health risks in different ways. When business travelers are worried about health risk, they may see it as a stress. Therefore, it is likely that health concern may explain how business travel is associated with perceived stress.

\subsection{Burnout}

Burnout refers to emotional, mental, and physical exhaustion due to depletion of energy resources (Pines \& Aronson, $1981^{[38]}$; Shirom, $1989^{[40]}$ ). Business travelers who experienced stress tended to report a higher level of burnout ${ }^{[42]}$. The experience of burnout is generally associated with high job demands and lack of job resources ${ }^{[18]}$. Put it in the context of business travel, business travelers' appraisal of job demands and resources associated with business travel might affect how burned-out business travelers experience. Therefore, burnout might be an important mechanism that explains the link between business travel and perceived stress.

People who experience burnout show emotional exhaustion, have cynical attitudes, and evaluate themselves in a negative light ${ }^{[35]}$. Showing symptoms of burnout at work will compromise job performance ${ }^{[5]}$. The consequences can be detrimental, especially when business travelers' primary responsibilities during business travel are to represent the organization.

\subsection{Social Support}

Social support is a psychosocial factor that benefits people. It increases well-being ${ }^{[32]}$ and reduces work stress ${ }^{[44]}$. Social support can come from one's social support network. At work, social support network includes colleagues and organization. Social support from supervisors could make recipients feel satisfied with and were more committed to their job and had lower intention to quit the job ${ }^{[2]}$. Social support from the organization enhances effective performance at work ${ }^{[47]}$. When employees perceived that the organization policies and benefits facilitated them to maintain work-family balance, they had higher levels of job satisfaction and commitment and a lower level of turnover intention ${ }^{[2]}$.

Social support network outside of workplace can include significant others, family members, and peers. Women provide social support to their working partners mainly by doing house chores ${ }^{[9]}$ and providing emotional support ${ }^{[43]}$. Men usually provide social support to their working partners by contributing to domestic chores and participating in child care, especially when the partners have extended work hours ${ }^{[10]}$. The sharing of domestic and child care responsibilities, although not evenly distributed, made women feel contented ${ }^{[10]}$ and less stressed ${ }^{[30]}$.

Therefore, social support might be an important factor that explains perceived stress in business travelers. Being away for business travel deprives their accessibility to social support networks which provide various forms of social support ${ }^{[45]}$. The low accessibility to social support network and resources might lead business travelers to appraise business travel as stressful.

\section{Aim and Theoretical Framework}

The main purpose of this study was to examine how business travel affects perceived stress among business travelers in Malaysia, and how health concerns, burnout, and social support mediate and explain this association (see Figure 1 for the conceptual framework). This study filled the gap in extant research by examining the mechanisms in the relationship between business travel and psychological stress in Malaysia. Research Considering the ways business travel was quantified in previous studies, the present study defined business travel as travel for business purposes that requires overnight lodging. There has been extensive research on business travel in the western countries; however there is a key difference in the biopsychosocial between western and Asian countries. Therefore, this study also works as a bridge to relate how the western and the Asian culture view the perceived stress arising from business travel.

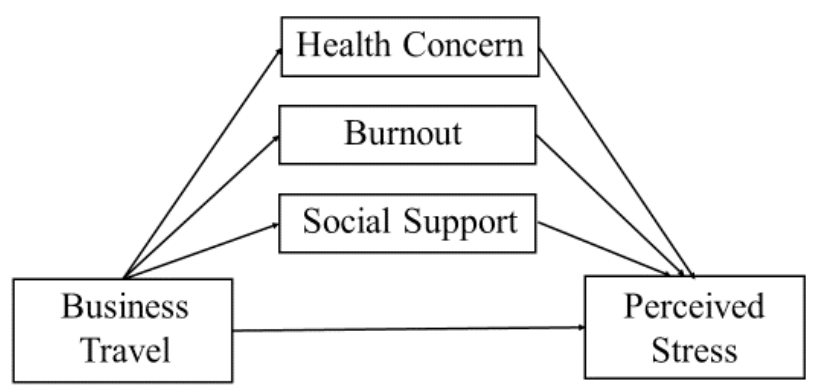

Figure 1. The conceptual model that depicts the hypothesized accountability of health concern, burnout, and social support in the association between business travel and perceived stress

We predicted that health concern, burnout, and social support would mediate the relationship between business travel and perceived stress. This hypothesis, following Baron and Kenny's (1986) ${ }^{[7]}$ and Hayes and Preacher's (2014) ${ }^{[29]}$ procedures, predicted that: 
1) Business travel would predict a higher level of perceived stress.

2) Business travel would predict higher levels of health concern and burnout and a lower level of social support.

3) Health concern and burnout would predict a higher level of perceived stress, and social support would predict a lower level of perceived stress.

4) The indirect effect of travel on perceived stress through the mediators would be significant.

We first examined how all the three mediators together explain the travel-stress association before examining how each mediator uniquely explains the association.

\section{Method}

\subsection{Participants and Design}

We recruited 100 working adults from Malaysia $(n=63$ men, $n=37$ women) with age ranged between 18 and 69 years old $(M=32.10, S D=12.36)$. See Table 1 for the demographic characteristics of the sample. The present study adopted a correlative approach by having participants complete a series of questionnaires using the paper-and-pencil method. This study chose the convenient sampling method to obtain basic data and trends regarding his study without the complications of using a randomized sample. This is to obtain an accurate representation of perceived stress among-st business travelers in Malaysia.

Table 1. Demographic Characteristics

\begin{tabular}{|c|c|c|c|}
\hline \multicolumn{2}{|c|}{ Characteristics } & $\mathbf{n}$ & $\%$ \\
\hline \multirow{2}{*}{ Gender } & Men & 61 & 62.20 \\
\hline & Women & 37 & 37.80 \\
\hline \multirow[t]{2}{*}{ Age } & $18-45$ & 82 & 83.70 \\
\hline & 46-above & 16 & 16.30 \\
\hline \multirow[t]{4}{*}{ Race } & Chinese & 25 & 25.50 \\
\hline & Malay & 37 & 37.80 \\
\hline & Indian & 23 & 23.50 \\
\hline & Others & 13 & 13.30 \\
\hline \multirow[t]{4}{*}{ Relationship Status } & Single & 44 & 44.90 \\
\hline & In a relationship & 12 & 12.20 \\
\hline & Engaged & 1 & 1.00 \\
\hline & Married & 41 & 41.80 \\
\hline \multirow[t]{2}{*}{ Religion } & Hinduism & 20 & 20.40 \\
\hline & Buddhism & 14 & 14.30 \\
\hline
\end{tabular}
of business travel, the predictor of the conceptual framework. This questionnaire comprised five major questions, which include the number of times an individual travels annually for business purposes that require overnight lodging, the distance of each trip, the duration of each trip, the duration (in hour) of the journey of each trip, and the mode of transportation. To obtain the business travel scores, we standardized all the variables (except for the last question) and summed up the standardized scores for each participant. Higher values denote more intensive business travel.

\subsubsection{Health Concern Questionnaire}

We used the 50-item Health Concern Questionnaire (Engs, 1970) ${ }^{[19]}$ to measure health concern, one of our mediators. In the present study, we replaced some older terminologies with new ones that fit better in the modern day. These included "nuclear warfare" that replaced "atomic warfare," "AIDS" that replaced "varicose veins," and "venereal disease" that replaced "sexually transmitted disease" (Engs, 1989) ${ }^{[20]}$. Responses to each item were scored from 1 (extremely concerned) to 5 (not concerned). When re-validating this questionnaire in 1989, Engs showed that this scale had high internal consistency, split-half reliability, and construct validity. The scale has a good internal consistency of .92 in our study. We averaged the scores of all items to obtain health concern scores, with higher scores indicating a higher level of concern for health.

\subsubsection{Burnout Measure Short Form}

We used the 10-item Burnout Measure Short Form (Malach-Pines, 2005) ${ }^{[34]}$ to measure burnout, one of the mediators. This scale is a short version of the Burnout Measure (Pines \& Aronson, 1988) ${ }^{[38]}$. The scale assesses a person's somatic, emotive, and psychological exhaustion levels on 
a Likert scale from 1 (never) to 7 (always). In validating the Burnout Measure Short Form, Malach-Pines compared the scale with the full Burnout Measure on samples of Israeli Jewish and Arab and samples of police officers, dialysis nurses, and MBA students. The results showed that the two scales were high correlated. Malach-Pines' study also reported high test-retest reliability and construct validity for the Burnout Measure Short form. The scale had a good internal consistency in our study $(\alpha=.98)$. We averaged the scores of the scale to obtain burnout scores, with higher scores indicating a higher level of burnout.

\subsubsection{The Duke-UNC Functional Social Support Questionnaire}

We administered this scale to measure social support, a mediator of the present study. This questionnaire is an eight-item instrument to measure the strength of the person's social support network (Broadhead, Gehlbach, De Gruy, \& Kaplan, 1988) ${ }^{[11]}$. Responses to each question are scored on a Likert scale from 1 (much less than I would like) to 5 (as much as I would like). Validity and reliability, which include construct validity, were found to be high in previous studies (Broadhead et al., 1988) ${ }^{[11]}$. The scale had high internal consistency $(\alpha=.86)$ in our study. We averaged the scores of all items to obtain social support scores, with higher scores indicating a higher level of social support.

\subsubsection{Perceived Stress Scale}

The 10-item version of Perceived Stress Scale (Cohen \& Williamson, 1988) ${ }^{[15]}$ examines the extent to which one perceived her/his life as stressful, uncontrollable, and unpredictable. Research showed that the scale had good construct validity, having significantly strong associations with other measures of similar constructs. For instance, the scale was strongly associated with the State-Trait Anxiety Inventory (Spielberger, 1983) ${ }^{[41]}$ that measures anxiety and Multidimensional Health Locus of Control (Wallston, Wallston, \& Devellis, 1978) ${ }^{[46]}$ that measures locus of control (Roberti, Harrington, \& Storch, 2006) ${ }^{[39]}$. The scale had a high internal consistency $(\alpha=.80)$ in our study. After reverse scoring, we averaged the responses to the 10 items to get perceived stress scores. Higher scores indicated a higher level of perceived stress.

5.2.6 Demographics Questionnaire.

This questionnaire asked questions such as gender, age, ethnicity, relationship status, religion, and how many children an individual has.

\subsection{Procedure}

Upon ethical approval, the experimenter (the first author of the paper) approached potential participants in Kuala Lumpur International Airport by first asking if they were traveling for business purposes. If they were, the experimenter gave them the information sheet and brief them on the purpose of the study. She also assured the potential participants of the confidentiality of their responses, the benefits and risks relating to the study, and the right of voluntary withdrawal from the study. If the potential participants agreed to participate in the study, the experimenter obtained informed consent from them.

Next, the participants completed a series of questionnaires described in the "Measures" subsection above. Upon completion, the experimenter debriefed participants with debrief sheets and thanked them for their participation. The questionnaire took approximately 10 to 15 minutes to complete, and there was no compensation for participants.

\section{Statistical Analysis Strategies}

The present study examined the association between business travel (predictor) and perceived stress (outcome), with health concern, burnout, and social support as the mediating factors. To test the hypotheses, we performed a mediation analysis by entering health concern, burnout, and social support simultaneously as mediators. Subsequently, to test the unique mediating effect of each mediator, we performed three mediation analyses by entering health concern, burnout, and social support respectively as the mediator.

We performed mediation analyses using PROCESS (Hayes, 2013) ${ }^{[28]}$ via SPSS MACRO. A mediation is established once the following conditions are satisfied: The predictor does or does not significantly predict the outcome (total effect; c path; Hayes, $2009^{[27]}$ ); the predictor significantly predicts the mediator(s) (a path); the mediator(s) significantly predicts the outcome (b path); the indirect effect of the predictor through the mediator(s) (i.e., (a) $\mathrm{x}(\mathrm{b})$ ) is significantly different from zero (ab path). To test the indirect effect, $95 \%$ confidence intervals (CIs) were constructed using 5,000 bootstrap re-sampling methods. The $95 \%$ CIs around the indirect effect from bootstrapping must exclude zero. In addition, we checked the direct effect (c' path), which is the effect of the predictor on the outcome after controlling for the mediator(s). If the direct effect is not significant, the mediation is a complete mediation, signifying that the mediator(s) explains all the variance in the predictor-outcome association. If the direct effect is significant, the mediation is a partial mediation, suggesting that the mediator(s) explains some of the variance. 


\section{Results}

\subsection{Assumption Verification and Preliminary Analyses}

The data violated the assumption of absence of univariate outlines when two values were 3.30 standard deviations away from the mean in perceived stress and business travel variables. The data also did not fulfill the assumption of absence of multivariate outliers as the maximum Mahalanobis distance exceeded the critical value (the critical value was 22.75, with $d f=5, \alpha=.001$ ). Two participants were both multivariate and univariate outlines. Thus, we removed the two participants from the data set, leaving the final sample size for hypothesis testing to be $98(n=$ 61 men, $n=37$ women). Table 2 shows the associations among business travel, perceived stress, mediators, and age.

Table 2. Correlation Coefficients among the Study Variables

\begin{tabular}{lcccccccc}
\hline \multicolumn{1}{c}{ Variables } & Mean & SD & 1 & 2 & 3 & 4 & 5 & 6 \\
\hline 1. Age & 31.98 & 12.42 & 1 & & & & & \\
2. Business Travel & 0.00 & 2.59 & $.43^{* *}$ & 1 & & & & \\
3. Health Concern & 2.69 & 1.03 & -.17 & -.12 & 1 & & & \\
4. Burnout & 3.10 & 0.84 & $-.25^{*}$ & $-.22^{*}$ & .19 & 1 & & \\
5. Social Support & 3.52 & 0.87 & -.04 & -.03 & -.12 & -.06 & 1 & \\
6. Perceived Stress & 1.90 & 0.51 & $-.27^{* *}$ & $-.25^{*}$ & .11 & $.47^{* *}$ & -.03 & 1 \\
\hline
\end{tabular}

Note. $\mathrm{SD}=$ standard deviation. ${ }^{*} \mathrm{p}<.05,{ }^{*} \mathrm{p}<.01$.

\subsection{Hypothesis Testing}

When the three mediators were considered as mediators simultaneously, business travel significantly predicted perceived stress, $b=-0.05, t=-2.42, p=.018$, and it explained $5.74 \%$ of the variability in perceived stress. More intense business travel was associated with a higher level of stress, a direction of association contrary to our prediction. Other conditions for mediation were not satisfied for health concern and social support. Specifically, business travel did not significantly predict health concern, $b=$ $-0.05, t=-1.24, p=.219$, and social support, $b=-0.01$, $t=-0.34, p=.734$. Health concern, $b=0.00, t=0.03, p$ $=.979$, and social support, $b=-0.01, t=-0.09, p=.922$, did not significantly predict perceived stress. The indirect effects of business travel and perceived stress through health concern, $Z=-0.02, S E=0.00,95 \% C I[-.01, .01]$, $a b_{c s}=-.00[-.03, .03]$, and social support, $Z=0.03, S E=$ $0.00,95 \% C I[-.01, .01], a b_{c s}=.00[-.03, .04]$, were not significant. However, the conditions for mediation were satisfied for burnout. Business travel significantly pre- dicted burnout, $b=-0.07, t=-2.09, p=.040$, and burnout significantly predicted perceived stress, $b=0.26, t=4.63$, $p<.001$. The indirect effect of business travel and perceived stress through burnout was significant, $Z=-1.87$, $S E=0.01,95 \% C I[-.04,-.00], a b_{c s}=-.02[-.04,-.00]$. After controlling for the three mediators, when people traveled more intensely, they reported a nonsignificantly lower level of perceived stress, $b=-0.03, t=-1.60, p=$ .113 , indicating a complete mediation (see Figure 2).

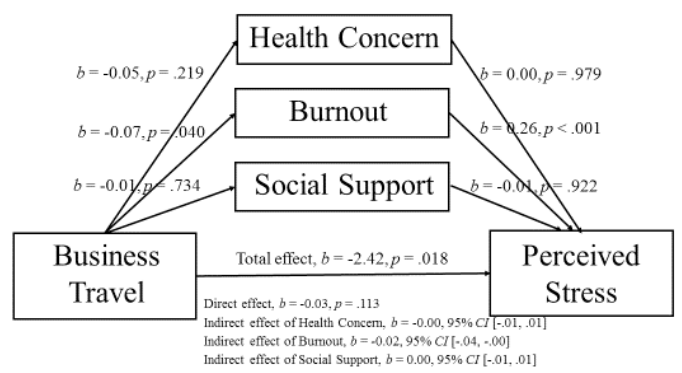

Figure 2. The mediating effects of health concern, burnout, and social support in the relationship between business travel and perceived stress when the three mediators were considered simultaneously

When only health concern was considered as a mediator, the conditions for mediation were not satisfied. Business travel significantly predicted perceived stress, $b=-0.05, t=-2.42, p=.018$, and it explained $5.74 \%$ of the variability in perceived stress. Next, business travel did not significantly predict health concern, $b=-0.05, t=$ $-1.24, p=.219$, and health concern did not significantly predict perceived stress, $b=0.04, t=0.78, p=.439$. The indirect effect of travel on perceived stress through health concern was not significant, $Z=-0.54, S E=0.00,95 \%$ $C I[-.02, .00], a b_{c s}=-.01[-.07, .01]$. After controlling for the mediator, when people traveled more intensely, they reported a significantly lower level of perceived stress, $b$ $=-0.05, t=-2.30, p=.024$.

When only burnout was considered as a mediator, the conditions for mediation were satisfied (see Figure 3). Business travel significantly predicted perceived stress, $b=-0.05, t=-2.42, p=.018$, and it explained $5.74 \%$ of the variability in perceived stress. Next, business travel significantly predicted burnout, $b=-0.07, t=-2.09, p=$ .040 , and burnout significantly predicted perceived stress, $b=0.27, t=4.77, p<.001$. The indirect effect of business travel on perceived stress through burnout was significant, $Z=-1.88, S E=0.01,95 \% C I[-.04,-.00], a b_{c s}=-.09[-.18$, -.02]. After controlling for the mediator, when people traveled more intensely, they reported a nonsignificantly lower level of perceived stress, $b=-0.03, t=-1.62, p=$ 
.108 , indicating a complete mediation effects of burnout in the effect of business travel on perceived stress.

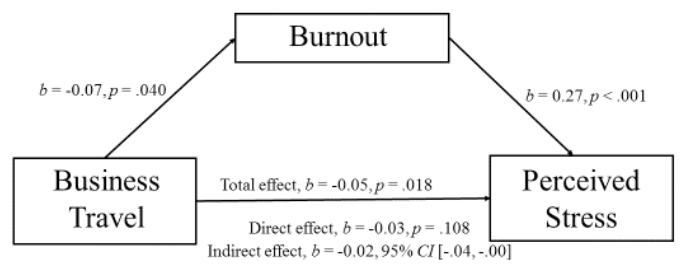

Figure 3. The unique mediating effect of burnout in the relationship between business travel and perceived stress

When only social support was considered as a mediator, the conditions for mediation were not satisfied. Business travel significantly predicted perceived stress, $b$ $=-0.05, t=-2.42, p=.018$, and it explained $5.74 \%$ of the variability in perceived stress. Business travel did not significantly predict social support, $b=-0.01, t=-0.34, p=$ .734 , and social support did not significantly predict perceived stress, $b=-0.02, t=-0.40, p=.689$. The indirect effect of business travel on perceived stress through social support was not significant, $Z=0.12, S E=0.00,95 \% \mathrm{CI}$ $[-.00, .01], a b_{c s}=0.00[-.02, .05]$. After controlling for the mediator, when people traveled more intensely, they reported a significantly lower level of perceived stress, $b=$ $-0.05, t=-2.42, p=.018$.

\section{Discussion}

The main purpose of the present study was to examine the underlying psychological mechanisms that explain the association between business travel and perceived stress in Malaysia. The underlying mechanisms examined were health concern, burnout, and social support. The mediation analysis with three mediators entered simultaneously showed that only burnout mediated the association between business travel and perceived stress. Similarly, when examining the unique mediating effect of each mediator, burnout completely mediated the relationship between business travel and perceived stress. Specifically, the less intensely an individual traveled, s/he experienced a higher level of burnout; a higher level of burnout was associated with a higher level of perceived stress. On the other hand, health concern and social support each did not mediate the relationship between business travel and perceived stress. These findings deepened our understanding of the psychological mechanisms that play an important role in travel stress.

\subsection{Theoretical Implications}

Based on the cognitive appraisal theory of stress (Folkman \& Lazarus, 1988) ${ }^{[25]}$ and previous studies in related area (e.g., Espino et al., 2002) ${ }^{[22]}$, we hypothesized that more intense business travel would predict higher levels of stress and burnout. However, contrary to our predicted direction, more intense business travel was associated with lower levels of perceived stress and burnout in our study.

There are several ways to explain this unexpected finding. First, technology advancement might have made business travel more convenient and hence less stressful. Espino and colleagues ${ }^{[22]}$ study that was conducted in early 2000 showed that business travel increased stress. Since early 2000 , the telecommunication technology has made great progress, making (business) travel more convenient. For instance, travelers nowadays manage itineraries and alerts via technologically-advanced mobile software applications ${ }^{[13]}$. Our participants who traveled more intensely might have utilized technology to make their business travel more convenient and hence felt less stressed about it. This explanation, however, does not explain all studies on travel stress that were conducted in the recent decade, such as a study conducted in $2013^{[26]}$ which showed that business travel was perceived as stressful.

Therefore, another way to explain the unexpected travel-stress association is that business travel has a respite effect. Frequent business travelers spend more time on business travel than at home, providing opportunities for them to detach themselves from ${ }^{[48]}$ and to be exempted from home responsibilities ${ }^{[8]}$. In addition, in our study, we approached participants at the airport right before they departed for their trips or after they completed their trips. For those who were departing for their trips, the respite effect might have just taken place ${ }^{[48]}$. After sorting out jobs at work, they were finally in the airport, anticipating their trip in a more relaxed mood. For those who had just returned from business trips, the trips might have ameliorated the stress they experienced prior to the trip ${ }^{[48]}$. Our study did not measure technology-facilitated travel convenience and respite effect of business travel, and hence future research should examine the mentioned factors.

Another important finding in our study was that burnout completely explained travel-stress association. Specifically, business travelers who traveled more intensely reported feeling less stressed, and this could be explained by the lower level of burnout they felt. This finding could be due to the greater resources frequent business travelers have. Those who travel more intensely and frequently are typically at higher positions in organizations. Their positions might allow them more control over their work and family domains ${ }^{[8]}$. On the other hand, our participants 
who traveled less intensely reported feeling more stressed, and this could be explained by the higher level of burnout they felt. For this group of travelers, burnout could be due to not getting used to conflict and excessive workload following business travel. These may include conflict between excessive workload from work and demand from family (Bacharach, Bamberger, \& Conley, 1991 ${ }^{[4]}$; Espino et al., $2002^{[22]}$ ) and additional follow-up paperwork ${ }^{[42]}$. Because they seldom travel, they might not be familiar with the procedure of follow-up paperwork and making arrangement to balance the demands from work and family.

Apart from the significant findings, our results showed that health concern could not explain the relationship between business travel and perceived stress. This result can be explained by travelers' unrealistically optimistic perception of travel risk. In assessing the risk associated with business travel, travelers might not be fully aware of the potential health hazards and hence are not concerned about their health. In a study by Zimmermann, Hattendorf, Blum, Nuesch, and Hatz (2013) ${ }^{[49]}$, when rating the risks associated with business travel, travelers rated certain risks, such as accidents and sexually transmitted infections, as having lower chances of happening than health experts' ratings. This over-optimistic perception existed even after a travel risk consultation ${ }^{[49]}$.

The results of the present study also showed that social support could not explain the relationship between business travel and perceived stress. A possible reason could be that a large number (58\%) of participants in this study had no children and therefore had lower need for social support. According to Fisher (1998) ${ }^{[23]}$, unmarried executives found business travel to be less stressful than the married executives with young families. Nearly 75 percent of the married travelers found it challenging to be away for long periods as compared with 50 percent of unmarried travelers. Another possible explanation could be that other aspects of social support, such as tangible support and organizational support, might have a greater role to play in explaining the travel-stress association. The present study measured the strength of social support network that provides functional support (i.e., the functions that a person in a support network can provide) and emotional support (i.e., having others listen to and show concern). However, social support is a broad concept that could encompass aspects other than those measured in the present study. Social support includes tangible support, which encompasses concrete and direct assistance from others ${ }^{[16]}$. Travel-specific tangible support may include direct assistance with making meals and assisting with childcare. Tangible support could be an important mediator in the relationship between business travel and perceived stress.
Moreover, social support may refer to organizational support received from the home office and receiving organization during business travel. In a qualitative study (Welch et al., 2007) ${ }^{[47]}$ that interviewed Australian and Danish international business travelers from various sectors, the respondents identified that having access to relevant contacts and networks from company networks was helpful in enhancing their performance during business travel.

\subsection{Practical Implication}

Our findings have shed some light on how to deal with business travel stress. Specifically, we found out that business travelers who traveled less intensely were more vulnerable to travel stress, and that burnout was an important mechanism that linked business travel to perceived stress.

There are several suggestions for organizations to promote the well-being of employees who have to travel for business purposes, especially those who travel less intensively. Our findings suggested that burnout plays an important role in travel stress. Therefore, organizations should review and implement policies that can decrease the feeling of burnout on business travelers. These policies should lighten the heavy workload of business travelers ${ }^{[6]}$, allow vacation time after concluding business assignments ${ }^{[42]}$ maintain web-based contact for travelers during business trips ${ }^{[47]}$, and provide concierge programs, such as childcare, pet care, and home repair ${ }^{[17]}$.

In addition, organizations should provide intervention programs that ameliorate business travelers' feeling of burnout. Specifically, programs that combine interventions that are person-directed, such as adaptive skill training and relaxation exercises, and interventions that are organization-directed, such as work process restructuring, led to longer lasting effect in reducing burnout ${ }^{[3]}$. To summarize, this research introduces a new frontier in business travel optimization by analyzing the mechanisms of stress and its impact on the traveler which helps organizations to tackle the hidden costs of business travel and optimize traveler well - being and productivity.

\subsection{Limitations and Suggestions for Future Stud- ies}

While our findings brought important theoretical and practical implications, the findings should be interpreted with care due to several limitations of the study. First, the present study used self-reported method to assess business travel that could be subject to memory biases. Future studies should quantify business travel in a more objective way, such as using the travel record from participants' organizations. Second, our participants filled out the questionnaires just before they set off for and after 
they completed business trips, when the respite effect of business travel might have taken place. We recommend future studies to approach participants at different timings, including during business trips and during normal work days, and control for the effect of timing on perceived stress. Thirdly, the sample size was too small in relation to the population of the study. We recommend future studies to take the big data approach to ensure that there is a better representative distribution of the population.

Although our findings revealed the important underlying mechanism of business travel stress, there are several factors that could explain our significant and non-significant findings. Further research is needed to test these factors to have a deeper understanding of business travel stress. We recommend future research to take into consideration of how familiar business travelers are with business travel, how convenient they perceive business travel to be, and how much of the convenience they experience is due to technology advancement. Moreover, we believe that the perception of resources available to cope with business travel, such as advanced technology, perceived control, and perceived vulnerability to accidents and diseases, is a factor that should not be neglected. Apart from these, future studies need a more holistic measure of social support, which includes measure of travel-specific tangible support and any forms of organizational support.

\section{Conclusion}

Business travel may bring profits to organizations, and it contributes to business travelers' professional development ${ }^{[36]}$. As business travel is gaining its importance to organizations and employees, we find it essential to encourage research on business travel stress. The present study found that the business travelers in Malaysia who traveled less intensely experienced a higher level of stress. Burnout could explain this association. For organizations that aim to promote the well-being of employees by implementing effective policies and interventions, such as training and workshops, our findings suggested that emphasis should be placed on business travelers with more attention on those who travel less intensively. In addition, the content of policies and intervention should focus on the ways to cope with and minimize burnout.

\section{References}

[ 1 ] Adler, N., \& Matthews, K. (1994). Health psychology: Why do some people get sick and some stay well? Annual Review of Psychology, 45, 229-259.

[ 2 ] Allen, T. (2001). Family-supportive work environ- ments: The role of organizational perceptions. Journal of Vocational Behavior, 58(1), 414-35.

[ 3 ] Awa, W. L., Plaumann, M., \& Walter, U. (2010). Burnout prevention: A review of intervention programs. Patient education and counseling, 78(2), 184190.

[ 4 ] Bacharach, S. B., Bamberger, P., \& Conley, S. (1991). Work-home conflict among nurses and engineers: Mediating the impact of role stress on burnout and satisfaction at work. Journal of Organizational Behavior, 12, 39-53.

[ 5 ] Bakker, A. B., Demerouti, E., \& Verbeke, W. (2004). Using the job demands-resources model to predict burnout and performance. Human Resource Management, 43, 83-104.

[ 6 ] Bakker, A. B., Le Blanc, P. M., \& Schaufeli, W. B. (2005). Burnout contagion among intensive care nurses. Journal of Advanced Nursing, 51(3), 276287.

[ 7 ] Baron, R. M., \& Kenny, D. A. (1986). The moderator-mediator variable distinction in social psychological research: Conceptual, strategic, and statistical considerations. Journal of Personality and Social Psychology, 51, 1173-1182.

[ 8 ] Batt, R., \& Valcour, P. M. (2003). Human resource practices as predictors of work-family outcomes and employee turnover. Industrial Relations: A Journal of Economy and Society, 42, 189-220.

[ 9 ] Berardo, D. H., Shehan, C. L., \& Leslie, G. R. (1987). A residue of tradition: Jobs, careers, and spouses' time in housework. Journal of Marriage and the Family, 49, 381-390.

[10] Bonney, J., Kelley, M. L., \& Levant, R. (1999). A model of fathers behavioral involvement in child care in dual-earner families. Journal of Family Psychology, 13(3), 401-15.

[11] Broadhead, W., Gehlbach, S., De Gruy, F., \& Kaplan, B. (1988). The Duke-UNC Functional Social Support Questionnaire: Measurement of social support in family medicine patients. Medical Care, 26, 709-723.

[12] Bryant, H. E., Csokonay, W. M., Love, M., \& Love, E. J. (1990). Self-reported illness and risk behaviours amongst Canadian tavellers while abroad. Canadian Journal of Public Health, 82, 316-319.

[13] Budd, L., Vorley, T. (2013). Airlines, apps, and business travel: A critical examination. Research in Transportation Business and Management, 9, 41-49.

[14] Carlson, D. \& Perrewe, P. (1999). The role of social support in the stressor-strain relationship: an examination of work-family conflict. Journal of Management, 25(4), 513-40.

[15] Cohen, S., \& Williamson, G. (1988). Perceived stress 
in a probability sample of the U.S.. In S. Spacapam \& S. Oskamp (Eds.), The social psychology of health: Claremont Symposium on Applied Social Psychology (pp. 31-67). Newbury Park, CA: Sage.

[16] Cohen, S., Mermelstein R., Kamarck T., \& Hoberman, H.M. (1985). Measuring the functional components of social support. In I.G. Sarason \& B. R. Sarason (Eds), Social support: Theory, research, and applications. The Hague, Netherlands: Martinus Niijhoff.

[17] DeFrank, R. S., Konopaske, R., \& Ivancevich, J. M. (2000). Executive travel stress: Perils of the road warrior. Academy of Management Executive, 14, 5871.

[18] Demerouti, E., Bakker, A. B., Nachreiner, F., \& Schaufeli, W. B. (2001). The job demands-resources model of burnout. Journal of Applied Psychology, $86,499-512$.

[19] Engs, R. (1970). The Health Concern Questionnaire. Unpublished Master's Thesis. University of Oregon, Eugene, OR. Retrieved from IUScholarWorks: http:// hdl.handle.net/2022/17250

[20] Engs, R. (1989). Assessing construct validity and re-assessing the reliability of the Health Concern Questionnaire. Retrieved from IUScholarWorks: http://hdl.handle.net/2022/17251

[21] Espino, C. M., Sundstrom, S. M., Frick, H. L., Jacobs, M., \& Peters, M. (2002). International business travel: Impact on families and travelers. Occupational and Environmental Medicine, 59, 309-322.

[22] Fisher, C. (1998). Business on the road. American Demographics, 20, 44-47.

24. Fisher, S., \& Cooper, C. (1990). On the move. New York: Wiley.

[23] Folkman, S., \& Lazarus, R. S. (1988). The relationship between coping and emotion: Implications for theory and research. Social Science and Medicine, 26, 309-317.

[24] Gustafson, P. (2013). Business travel from the traveller's perspective: Stress, stimulation and normalization. Mobilities, 9, 63-83.

[25] Hayes, A. F. (2009). Beyond Baron and Kenny: Statistical mediation analysis in the new millennium. Communication Monographs, 76, 408-420.

[26] Hayes, A. F. (2013). Introduction to mediation, moderation, and conditional process analysis: A regression-based approach. New York, NY: Guilford Press.

[27] Hayes, A. F., \& Preacher, K. J. (2014). Statistical mediation analysis with a multicategorical independent variable. British Journal of Mathematical and Statistical Psychology, 67(3), 451-470.

[28] Hoffman, L. W. (1989). Effects of maternal employ- ment in the two-parent family. American Psychologist, 44, 283-292.

[29] Hooker, J. (2012). Cultural differences in business communication (pp. 389-407). In C. B. Paulston, S. F. Kiesling \& E. S. Rangel (Eds.), The Handbook of Intercultural Discourse and Communication. Chichester, UK: John Wiley \& Sons.

[30] House, J. S., Landis, K. R., \& Umberson, D. (1988). Social relationships and health. Science, 241, 540545.

[31] Liese, B., Mundt, K. A., Dell, L. D., Nagy, L., \& Demure, B. (1997). Medical insurance claims associated with international business travel. Occupational and Environmental Medicine, 54, 499-503.

[32] Malach-Pines, A. (2005). The Burnout Measure, Short Version. International Journal of Stress Management, 12, 78-88.

[33] Maslach, C., \& Jackson, S. E. (1981). The measurement of experienced burnout. Journal of Occupational Behaviour, 2, 99-113.

[34] Oddou, G., Mendenhall, M. E., \& Ritchie, J. B. (2000). Leveraging travel as a tool for global leadership development. Human Resource Management, 39, 159-172.

[35] Penney, L. M., \& Spector, P. E. (2005). Job stress, incivility, and counterproductive work behavior (CWB): The moderating role of negative affectivity. Journal of Organizational Behavior, 26, 777-796.

[36] Pines, A., \& Aronson, E. (1981). Burnout: From tedium to personal growth. New York: Free Press.

[37] Roberti, J. W., Harrington, L. N., \& Storch, E. A. (2006). Further psychometric support for the 10-item version of the perceived stress scale. Journal of College Counseling, 9(2), 135-147.

[38] Shirom, A. (1989). Burnout in work organizations (pp. 25-48). In C. L. Cooper (Ed.), International Review of Industrial and Organizational Psychology. Oxford, England: John Wiley \& Sons.

[39] Spielberger, C. D. (1983). Manual for the State-Trait Anxiety Inventory: STAI (Form T). Palo Alto, CA: Mind Garden.

[40] Striker, J., Luippold, R. S., Nagy, L., Liese, B., Bigelow, C., \& Mundt, K. A. (1999). Risk factors for psychological stress among international business travelers. Occupational and Environmental Medicine, $56,245-252$.

[41] Vinokur, A. D., \& Vinokur-Kaplan, D. (1990). "In sickness and in health:" Patterns of social support and undermining in older married couples. Journal of Aging and Health, 2, 215-241.

[42] Viswesvaran, C., Sanchez, J. I., \& Fisher, J. (1999). The role of social support in the process of work 
stress: A meta-analysis. Journal of Vocational Behavior, 54, 314-334.

[43] Voydanoff, P. (2005). Work demands and work-to-family and family-to-work conflict: Direct and indirect relationships. Journal of Family Issues, 26, 707-726.

[44] Wallston, K. A., Wallston, B. S., \& Devellis, R. F. (1978). Development of the Multidimensional Health Locus of Control scale (MHLC). Health Education Monographs, 6, 160-170.

[45] Welch, D. E., Welch, L. W., \& Worm, V. (2007). The international business traveler: A neglected but strategic human resource. International Journal of Human Resource Management, 18, 173-183.

[46] Westman, M., \& Etzion, D. (2002). The impact of short overseas business trips on job stress and burnout. Applied Psychology, 51(4), 582-592.

[47] Zimmermann, R., Hattendorf, J., Blum, J., Nüesch, R., \& Hatz, C. (2013). Risk perception of travelers to tropical and subtropical countries visiting a Swiss travel health center. Journal of Travel Medicine, 20, 3-10. 